Revta brasil. Bot., São Paulo, V.24, n.2, p.199-204, jun. 2001

\title{
Alteração no potencial osmótico e teor de carboidratos solúveis em plantas jovens de lobeira (Solanum lycocarpum St.-Hil.) em resposta ao estresse hídrico ${ }^{1}$
}

\author{
JALES TEIXEIRA CHAVES FILHO ${ }^{2}$ e ELIANE STACCIARINI-SERAPHIN ${ }^{2,3}$
}

(recebido: 4 de julho de 2000; aceito: 23 de fevereiro de 2001)

\begin{abstract}
Change in osmotic potential and soluble carbohydrates levels in Solanum lycocarpum St.-Hil. in response to water stress). Solanum lycocarpum is a typical species from the "cerrado" vegetation in Central Brazil and has shown drought resistance under environmental conditions. Osmotic adjustment refers to a decrease in osmotic potential caused by accumulation of solutes and the continuous accumulation of solutes must occur in tissues to maintain the water potential gradient necessary for cell enlargement and turgor maintenance. The influence of water stress on osmotic potential and soluble carbohydrate levels was investigated in this research. The analyses of the results showed a decrease in osmotic potential in response to water stress. An increase in the carbohydrate levels was observed in plants under stress conditions in greenhouse. Reducing sugars were the major contributors to soluble carbohydrates levels detected in leaves and roots. These results suggested that Solanum lycocarpum plants showed a mechanism of adaptation to survival in water stress conditions.
\end{abstract}

RESUMO - (Alteração no potencial osmótico e teor de carboidratos solúveis em plantas jovens de lobeira (Solanum lycocarpum St.-Hil.) em resposta ao estresse hídrico). Solanum lycocarpum é uma espécie típica da vegetação do cerrado brasileiro e tem demonstrado resistência à seca que ocorre em seu ambiente. O ajustamento osmótico é um decréscimo do potencial osmótico causado pelo acúmulo de solutos nas células, o qual mantém o gradiente de potencial hídrico e, ao mesmo tempo, a turgescência necessária ao crescimento celular. A influência do estresse hídrico no potencial osmótico e no teor de carboidratos solúveis foi investigada neste trabalho. A análise dos resultados mostrou que as plantas de Solanum lycocarpum apresentaram redução significativa nos valores de potencial osmótico em resposta ao estresse hídrico. O aumento no teor de carboidratos solúveis foi verificado em plantas sob condições estressantes em casa de vegetação, em particular o de carboidratos redutores. Os resultados obtidos sugerem que esta espécie apresenta mecanismo de ajustamento osmótico, nas condições de estresse hídrico, adaptando-a à sobrevivência nessa condição.

Key words - Osmotic adjustment, water stress, "cerrado" vegetation, savannah, carbohydrate

\section{Introdução}

As plantas durante seu ciclo de vida nem sempre encontram condições ambientais onde todos os fatores sejam favoráveis ao seu crescimento e desenvolvimento. Um importante fator ambiental que limita o crescimento é a redução na disponibilidade de água do solo. O estresse hídrico ocorre geralmente, na natureza, de maneira gradual e as plantas tolerantes desenvolveram mecanismos para se adaptarem às condições de baixa disponibilidade de água no solo.

A capacidade apresentada pelas plantas de terem uma produção satisfatória em áreas sujeitas a déficit hídrico é referida como resistência à seca (Turner 1997). Dependendo dos mecanismos

1. Parte da dissertação de mestrado de J.T. Chaves-Filho.

2. Universidade Federal de Goiás, Departamento de Biologia Geral, Caixa Postal 131, 74 001-970 Goiânia, GO, Brasil.

3. Autor para correspondência: eliane@icb1.ufg.br desenvolvidos para resistirem à seca, as plantas são classificadas em três categorias principais: a) espécies que escapam da seca (rápido desenvolvimento fenológico), b) espécies que toleram a seca com alto potencial hídrico (adiam a desidratação) e c) espécies que toleram a seca com baixo potencial hídrico (toleram a desidratação) (Turner 1986, 1997).

O acúmulo intracelular de solutos osmoticamente ativos em resposta às condições estressantes de baixa disponibilidade de água e salinidade é um importante mecanismo desenvolvido pelas plantas que toleram a seca com baixo potencial hídrico (Turner 1986). Este mecanismo, denominado ajustamento osmótico (Munns 1988), tem sido verificado em várias espécies (Morgan 1984) e é considerado um dos mais eficazes para manutenção da turgescência celular, permitindo principalmente a manutenção da abertura estomática e fotossíntese sob condições de baixo potencial hídrico no solo (Lawlor \& Leach 1985, Turner 1986, Funkhouser et al. 1994, Kramer 
1995). Embora o ajustamento osmótico não impeça que a taxa fotossintética seja reduzida sob condições de estresse hídrico (Jones \& Rawson 1979), a manutenção da turgescência permite que a fotossíntese e outras importantes atividades fisiológicas sejam mantidas, mesmo que baixas, possibilitando a redistribuição de carbono e nitrogênio (Kobata et al. 1992, Palta et al. 1994).

A importância e contribuição dos solutos envolvidos no ajustamento osmótico em resposta à baixa disponibilidade de água varia com a espécie (Morgan 1984). Em forrageiras tropicais, o potássio e o cloro foram apontados como sendo os solutos que mais contribuem (Ford \& Wilson 1981) enquanto que em soja, os principais solutos acumulados foram os aminoácidos, a glicose, a frutose e a sacarose (Meyer \& Boyer 1981).

A importância do ajustamento osmótico no estabelecimento e produtividade de plantas cultivadas em resposta ao estresse hídrico tem sido bastante estudada (Morgan 1984, Turner 1986, 1997). Entretanto, a literatura para plantas nativas é ainda incipiente, especialmente no cerrado, onde a precipitação ocorre de maneira sazonal. Em Vernonia herbacea, estudos realizados por Figueiredo-Ribeiro (1993) mostraram a presença de frutanos nos órgãos subterrâneos de reserva e que o estresse hídrico estimula sua hidrólise, colocando este polissacarídeo como candidato a uma função protetora em condições de baixa disponibilidade de água.

A espécie Solanum lycocarpum St.-Hil., conhecida popularmente como lobeira ou fruta-de-lobo (Cruz 1979, Silva 1996, Almeida et al. 1998), é uma espécie arbórea típica do cerrado brasileiro (Rizzini 1971). A lobeira apresenta importância ecológica neste ecossistema por servir de alimento para o lobo-guará (Chrysocyon brachyurus Illiger, 1811) e outros mamíferos do cerrado, além de possuir propriedades medicinais (Cruz 1979, Almeida et al. 1998). Alguns autores citam a lobeira como sendo espécie de interesse para o cultivo, uma vez que seus frutos são comestíveis, muito aromáticos e são utilizados para o preparo de doces (Silva 1996, Almeida et al. 1998). Estudos sobre o desenvolvimento inicial de Solanum lycocarpum em casa de vegetação, demonstraram que em condição de baixa disponibilidade de água ocorreu um maior desenvolvimento do sistema radicular (Vidal et al. 1999) indicando adaptação da espécie às condições de estresse hídrico.

Considerando a importância ecológica de $S$. lycocarpum e seu potencial como planta medicinal e passível de aproveitamento econômico, informações concernentes a esta espécie são relevantes, uma vez que os dados de literatura são, ainda, incipientes. Desta forma, o objetivo deste trabalho foi investigar se essa espécie apresenta redução do potencial osmótico bem como alterações nos teores de carboidratos solúveis em resposta ao estresse hídrico, caracterizando um possível ajustamento osmótico como mecanismo de adaptação ao seu ambiente natural.

\section{Material e métodos}

Foram utilizadas plantas jovens de Solanum lycocarpum St.-Hil. com 190 dias contados após a semeadura. As plantas foram obtidas através da germinação de sementes e cresceram em casa de vegetação do Instituto de Ciências Biológicas da Universidade Federal de Goiás (UFG).

Antes do plantio as sementes foram escarificadas e embebidas em água destilada durante $24 \mathrm{~h}$ e semeadas em sacos plásticos pretos, contendo aproximadamente $2 \mathrm{~kg}$ de uma mistura de latossolo-vermelho e areia (2:1). Duas sementes foram introduzidas a uma profundidade de $1,5 \mathrm{~cm}$ no substrato que foi previamente umedecido com água até atingir a capacidade de campo (CC).

O substrato foi irrigado a cada três dias para a manutenção da CC até o momento de aplicação do tratamento de estresse hídrico, que se iniciou aos 190 dias após a semeadura. No controle, a irrigação foi realizada diariamente durante 20 dias, mantendo o solo em CC. No tratamento de estresse restringiu-se o fornecimento de água, adicionando-se somente $40 \%$ do controle, a cada recipiente, durante 20 dias.

Ao final do período experimental, quando as plantas estavam com a idade de 210 dias, foram coletadas a primeira, a segunda e a terceira folhas contadas a partir da folha apical (folha não expandida localizada no ápice da planta) respectivamente para dosagem de carboidratos solúveis, determinação do potencial osmótico e do conteúdo relativo de água (CRA). As folhas para a determinação do CRA foram amostradas às 7:00 h. O teor de carboidratos solúveis foi também dosado em amostras de raízes provenientes das mesmas plantas. Após a coleta das amostras vegetais, recolheu-se amostra do substrato para a determinação do teor de umidade (TUS).

A determinação do potencial osmótico foi realizada a partir de $100 \mu \mathrm{L}$ de extrato de cada amostra, utilizando o microsmômetro automático Roebling. Os valores fornecidos em miliosmol (mosm) foram convertidos para MegaPascal (MPa).

Para a dosagem do teor de carboidratos solúveis totais, utilizou-se o método de antrona (Spiro 1966). Para a dosagem do teor de sacarose utilizou-se também o método de antrona, porém degradando-se os carboidratos redutores mediante a ação do 
hidróxido de potássio como descrito por Riazi et al. (1985). A estimativa do teor de carboidratos redutores em cada amostra foi obtida subtraindo-se os valores dos carboidratos solúveis totais dos valores obtidos para a sacarose.

O conteúdo relativo de água nas folhas de plantas com 210 dias foi obtido para cada amostra através da determinação da massa fresca, massa túrgida e massa seca das folhas de acordo com Hall et al. (1993).

O teor de umidade do substrato de crescimento das plantas aos 210 dias após o plantio foi determinado através da obtenção da massa úmida e da massa seca das amostras como indicado por Marshal et al. (1996).

Para a comparação dos dados de potencial osmótico, carboidratos solúveis, TUS e CRA utilizou-se o teste t de Student.

\section{Resultados e Discussão}

Plantas de Solanum lycocarpum do controle não mostraram variação no potencial osmótico das folhas, que foi de $-0,8 \pm 0,038 \mathrm{MPa}$. Nas plantas tratadas, observou-se uma redução significativa do potencial osmótico foliar que foi igual a $-1,02 \pm$ $0,02 \mathrm{MPa}$ (figura 1A). A redução do teor de umidade do substrato (TUS) de $23,28 \%$ para $7,01 \%$, foi observada com o tratamento de estresse hídrico, através da restrição no fornecimento de água durante 20 dias (figura 1B). O valor encontrado neste tratamento $(7,01 \%)$ está abaixo do teor de água indicado para solos em ponto de murcha permanente (Kramer 1995).

Embora tanto o potencial osmótico das folhas como o teor de umidade do substrato tenham sido significativamente reduzidos em resposta ao tratamento, o conteúdo relativo de água (CRA) das folhas não apresentou diferença significativa, sendo $92,85 \%$ para as plantas controle (CC) e $90,64 \%$ para as plantas tratadas (figura 1C).

A absorção de água pelas raízes, juntamente com a evaporação através da superfície do solo, causaram a redução do TUS abaixo do ponto de murcha permanente no tratamento de estresse hídrico. Mesmo com baixo teor de umidade no substrato, as plantas de $S$. lycocarpum foram capazes de manter seu teor hídrico foliar em níveis iguais aos das plantas em substrato em capacidade de campo (figura 1C), possivelmente devido ao fechamento estomático e à manutenção da absorção.

Uma vez que o CRA não foi afetado pelo tratamento o abaixamento do potencial osmótico em plantas de $S$. lycocarpum em resposta ao déficit hídrico pode ser atribuído ao aumento na
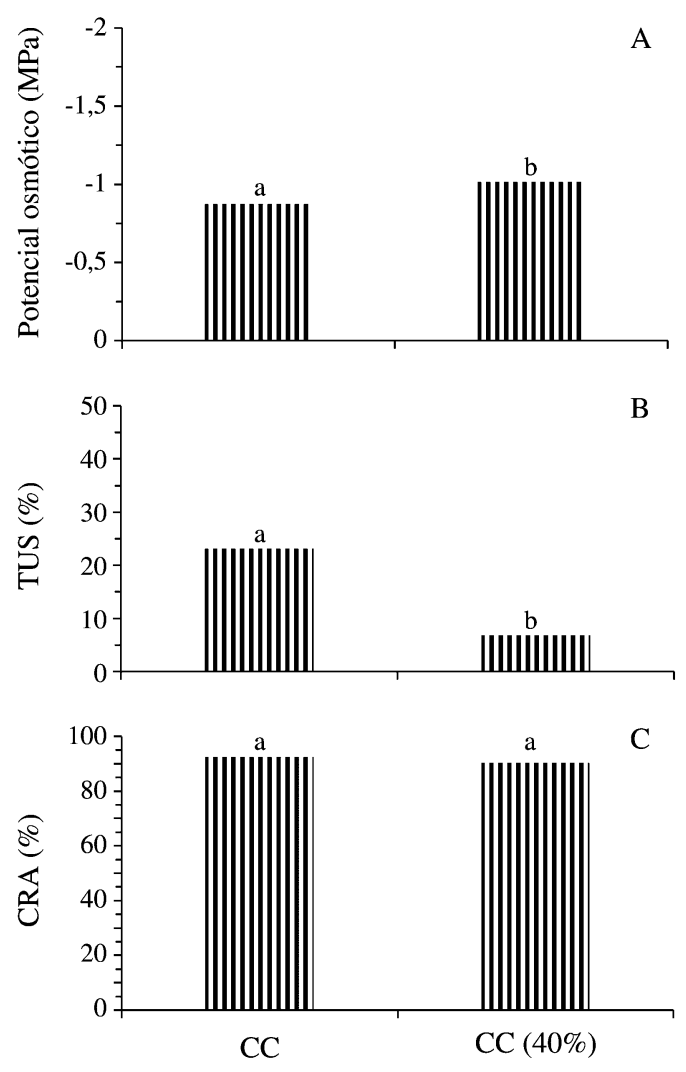

Figura 1. Potencial osmótico (A) em folhas, teor de umidade do substrato (TUS) (B) e conteúdo relativo de água (CRA) (C) nas folhas de Solanum lycocarpum crescendo em casa de vegetação com substrato em capacidade de campo (CC) e com restrição hídrica (CC (40\%)). Letras minúsculas comparam as médias entre os tratamentos.

concentração intracelular de solutos. Segundo Kramer (1995), a adição de solutos osmoticamente ativos às células é mais eficaz em promover o abaixamento do potencial hídrico do que a própria perda de água. Uma redução de $10 \%$ no volume do vacúolo celular, provoca diminuição no potencial osmótico em cerca de $11 \%$ do valor inicial, sendo, entretanto, a adição de solutos responsável por redução de até $50 \%$ no valor do potencial osmótico da célula (Kramer 1995). Assim, o ajustamento osmótico permite que o crescimento celular ocorra sob um potencial hídrico que geralmente seria inibidor de tal condição. Ele também auxilia a manutenção da abertura estomática e o funcionamento do aparelho fotossintético, 
permitindo que este opere mesmo em condições de baixo potencial hídrico (Turner 1997).

O acúmulo de solutos osmoticamente ativos nas células faz com que o potencial osmótico e o potencial hídrico da planta abaixem mais rapidamente que o do solo, aumentando o gradiente de potencial hídrico (Turner \& Jones 1980).

Os dados obtidos para S. lycocarpum estão de acordo com os resultados de Cutler et al. (1980) que, embora tenham estudado outra espécie, verificaram o ajustamento osmótico em quatro cultivares de plantas de arroz (Oriza sativa), em resposta ao estresse hídrico. Esses autores mostraram um abaixamento de 0,3 a 0,5 MPa no potencial osmótico das folhas para o mesmo conteúdo relativo de água, quando comparado ao controle.

A dosagem dos teores de carboidratos solúveis totais e redutores em folhas e raízes de $S$. lycocarpum, demonstrou que os níveis desses compostos aumentaram significativamente em resposta ao tratamento de estresse hídrico (tabela 1), sendo que os açúcares redutores foram os que mais contribuíram para esse aumento. Resultados semelhantes foram encontrados por Marur (1998) em plantas de Gossypium hirsutum L. sob condições de estresse hídrico, que apresentaram teor de amido reduzido e níveis de açúcares redutores aumentados. Paula et al. (1989) verificaram, na mesma espécie, uma redução no potencial osmótico foliar em resposta ao estresse hídrico.

Os teores de carboidratos solúveis totais e redutores nas folhas de plantas tratadas foram iguais a 70,80 mg.g ${ }^{-1}$ MS e $63,65 \mathrm{mg} \cdot \mathrm{g}^{-1} \mathrm{MS}$ respectivamente, diferindo dos teores apresentados pelas plantas controle que foram de $52,84 \mathrm{mg} . \mathrm{g}^{-1} \mathrm{MS}$ e 45,99 mg. $\mathrm{g}^{-1} \mathrm{MS}$ (tabela 1 ). As raízes das plantas tratadas apresentaram também maiores teores de carboidratos solúveis totais $\left(127,70 \mathrm{mg} \cdot \mathrm{g}^{-1} \mathrm{MS}\right)$ e de

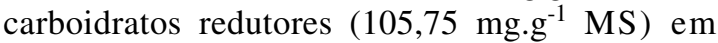
comparação com as plantas controle, com teores de carboidratos solúveis totais de $89,70 \mathrm{mg} \mathrm{g}^{-1} \mathrm{MS}$ e de carboidratos redutores de 71,09 $\mathrm{mg} . \mathrm{g}^{-1} \mathrm{MS}$ (tabela 1). Embora o tratamento de estresse hídrico tenha provocado aumento nos teores de carboidratos solúveis totais e redutores tanto nas folhas como nas raízes, os teores de sacarose não apresentaram diferenças significativas entre os grupos controle e tratado (tabela 1), indicando que a taxa fotossintética foi mantida mesmo em condições de baixa disponibilidade de água no solo.

O aumento no teor de carboidratos solúveis totais foi observado também por Irigoyen et al. (1992) em folhas de alfafa (Medicago sativa) como resposta ao estresse hídrico. Os teores de carboidratos solúveis totais foram de $90 \mathrm{mg} \cdot \mathrm{g}^{-1} \mathrm{MS}$ para um potencial hídrico de $-1,5 \mathrm{MPa}$ e de $170 \mathrm{mg} \cdot \mathrm{g}^{-1} \mathrm{MS}$ para potencial hídrico de $-2,8 \mathrm{MPa}$ nas folhas.

Os resultados para S. lycocarpum demonstraram que a razão sacarose/carboidratos redutores foi aproximadamente o dobro nas raízes em comparação com as folhas, tanto em plantas controle como tratadas. Essa razão foi sempre menor no tratamento em ambos os órgãos, indicando que o estresse hídrico causou uma alteração na proporção dos carboidratos redutores, uma vez que os níveis de sacarose permaneceram constantes. Importantes enzimas como as amilases e a invertase, entre outras, podem ter atuado neste processo.

Segundo Kramer (1995), a seca exerce importante influência no teor de carboidratos em diversas espécies. Em virtude do efeito da seca o amido é degradado nos tecidos que o acumulam; a redução na quantidade de amido é uma consequiência

Tabela 1. Teor de carboidratos solúveis totais, sacarose e carboidratos redutores em folhas e raízes de Solanum lycocarpum crescendo em casa de vegetação com substrato em capacidade de campo (CC) e com restrição hídrica (CC 40\%). As letras comparam as médias entre os tratamentos no mesmo órgão.

\begin{tabular}{lccccc}
\hline Carboidratos (mg.g & \multicolumn{2}{c}{ Folhas } & & \multicolumn{2}{c}{ Raízes } \\
\cline { 2 - 3 } \cline { 5 - 6 } & $\mathrm{CC}$ & $\mathrm{CC}(40 \%)$ & $\mathrm{CC}$ & $\mathrm{CC}(40 \%)$ \\
\hline Carboidratos totais & $52,84 \mathrm{~A}$ & $70,80 \mathrm{~B}$ & & $89,70 \mathrm{~A}$ & $127,70 \mathrm{~B}$ \\
Sacarose & $6,85 \mathrm{~A}$ & $7,15 \mathrm{~A}$ & & $18,61 \mathrm{~A}$ & $21,95 \mathrm{~A}$ \\
Carboidratos redutores & $45,99 \mathrm{~A}$ & $63,65 \mathrm{~B}$ & & $71,09 \mathrm{~A}$ & $105,75 \mathrm{~B}$ \\
Sacarose/Carboidratos redutores & 0,14 & 0,11 & & 0,26 & 0,20 \\
\hline
\end{tabular}


da atividade da amilase, sendo acompanhada por um aumento da quantidade de açúcares solúveis redutores. Na maioria das plantas, a sacarose é o principal açúcar exportado dos locais de síntese (folhas) para as regiões de consumo (caule, gemas vegetativas, raízes e órgãos reprodutivos) onde será utilizada para o crescimento e/ou armazenamento. As hexoses liberadas a partir da hidrólise de sacarose podem ser utilizadas em processos anabólicos ou catabólicos e também fornecendo açúcares redutores para o processo de ajustamento osmótico. Dentre as enzimas que participam dessa hidrólise, as invertases parecem ser mais ativas do que a sacarose sintase (Kingston-Smith et al. 1999). Marur (1999) verificou que em algumas variedades de plantas de algodoeiro submetidas ao estresse hídrico ocorreu um ajustamento osmótico como consequiência do acúmulo de solutos no simplasto, apresentando um aumento no teor de carboidratos redutores, que se mostrou associado à diminuição do potencial hídrico.

Segundo Ferri (1980), a vegetação nativa dos cerrados, em geral, não é decídua e, mesmo no auge da seca não sofre em conseqüência da falta de água, pois quase não se verificam sinais de murcha e muitas plantas entram em brotação vegetativa ou floral, ou suas sementes germinam. Entretanto, não se pode concluir que essas plantas perenes sejam de fato insensíveis à acentuada desidratação das camadas superiores do solo durante a estação seca. Tudo indica que elas são plantas fisiologicamente adaptadas à condição de "aridez sazonal" invariavelmente associada à existência dos cerrados, como afirma Alvim (1996). Estudos recentes (Franco 2000 e referências aí citadas) mostram que plantas lenhosas do cerrado respondem às condições ambientais com inúmeros mecanismos, tanto morfológicos como fisiológicos, e a estrutura da comunidade é muito mais complexa do que se pensou inicialmente.

Dentro desse contexto, os resultados obtidos no presente trabalho, permitiram concluir que a espécie Solanum lycocarpum St.-Hil. apresenta um acúmulo de solutos, com reflexos no abaixamento do potencial osmótico, como uma resposta ao estresse hídrico, caracterizando um ajustamento osmótico. Este mecanismo é, provavelmente, uma das estratégias que, atuando em conjunto com outros fatores, permitem à espécie sobreviver em condições estressantes que ocorrem em seu ambiente natural.

Agradecimentos - À CAPES, FINEPE e PRIPE/FUNAPE pelo apoio financeiro.

\section{Referências bibliográficas}

ALMEIDA, S.P., PROENÇA, C.E., SANO, S.M. \& RIBEIRO, J.F. 1998. Cerrado: Espécies Vegetais Úteis. EMBRAPA, Planaltina.

ALVIM, P.T. 1996. Repensando a teoria da formação dos campos cerrados. In Anais do VIII Simpósio sobre o Cerrado. (R.C. Pereira \& L.C.B. Nasser, eds). EMBRAPA/CPAC, Brasília, p.56-58.

CRUZ, G.L. 1979. Dicionário das Plantas Úteis do Brasil. Civilização Brasileira, Rio de Janeiro, 599 p.

CUTLER, J.M., SHAHAN, K.W. \& STEPONKUS, P.L. 1980. Alteration of the internal water relations of rice in response to drought hardening. Crop Science 20:307-310.

FERRI, M.G. 1980. Breve histórico das mais importantes linhas de pesquisa no cerrado. In Cerrado: Uso e Manejo. (D. Marchetti \& A.D. Machado, eds.). Editerra, Brasília, p.27-35.

FIGUEIREDO-RIBEIRO, R.C.L. 1993. Distribuição, aspectos estruturais e funcionais dos frutanos, com ênfase em plantas herbáceas do cerrado. Revista Brasileira de Fisiologia Vegetal 5:203-208

FORD, C.W. \& WILSON, J.R. 1981. Changes in levels of solutes during osmotic adjustment to water stress in leaves of four tropical pasture species. Australian Journal of Plant Physiology 8:77-91.

FRANCO, A.C. 2000. Water and light use strategies by cerrado wood plants. In Tópicos atuais em botânica (T.B. Cavalcanti \& B.M.T. Walter, coords.) SBB, EMBRAPA/CPAC, Brasília, p.292-298.

FUNKHOUSER, E.A., CAIRNEY, J., CHANG, S., DIAS, M.A.D.L. \& NEWTON, R.J. 1994. Cellular and molecular responses to water deficits stress in woody plants. In Handbook of plant and crop stress (M. Pessaralakli, ed.). Marcel Dekker Inc., New York, p.347-362.

HALL, D.O., SCURLOCK, J.M.O., BOLHARNORDENKAMPF, H.R., LEEGOOD, R.C. \& LONG, S.P. 1993. Photosynthesis and production in a changing environment: A field and laboratory manual. Chapman \& Hall, London.

IRIGOYEN, J.J., EMERICH, D.W. \& SÁNCHEZ-DÍAZ, M. 1992. Water stress induced changes in concentrations of proline and total soluble sugars in nodulated alfalfa (Medicago sativa) plants. Physiolgia Plantarum 84:55-60.

JONES, M.M. \& RAWSON, H.M. 1979. Influence of the rate of development of leaf water deficits upon photosynthesis, leaf conductance, water use efficiency, and osmotic potential in sorghum. Physiolgia Plantarum 45:103-111.

KINGSTON-SMITH, A.H., WALKER, R.P. \& POLLOCK, C.J. 1999. Invertase in leaves: conundrum or control point? Journal of Experimental Botany 50:735-743. 
204 J.T. Chaves-Filho \& E. Stacciarini-Seraphin: Potencial osmótico e teor de carboidratos em Solanum lycocarpum

KOBATA, T., PALTA, J.A. \& TURNER, N.C. 1992. Rate of development of postanthesis water deficits and grain filling in spring wheat. Crop Science 32:1238-1242.

KRAMER, P.J. 1995. Water relations of plants and soils. Academic Press, London.

LAWLOR, D.W. \& LEACH, J.E. 1985. Leaf growth and water deficits: Biochemistry in relation to biophysics. In Society for Experimental Biology (R.N. Baker, W.J. Davies \& C.K. Ong, eds.). Seminar Series, 27. Cambridge University Press, Cambridge, p.267-294.

MARSHAL, T.J., HOLMES, J.W. \& ROSE, C.W. 1996. Soil physics. 3 ed. Cambridge University Press, Cambridge.

MARUR, C.J. 1998. Fotossíntese e translocação de carboidratos em algodoeiros submetidos a déficit hídrico após a aplicação de cloreto de mepiquat. Revista Brasileira de Fisiologia Vegetal 10:59-64.

MARUR, C.J. 1999. Curvas pressão-volume e expansão foliar em cultivares de algodoeiro submetidos a déficit hídrico. Scientia Agricola 56:563-569.

MEYER, R.F. \& BOYER, J.S. 1981. Osmoregulation, solute distribution, and growth in soybean seedlings having low water potentials. Planta 151:482-489.

MORGAN, J.M. 1984. Osmoregulation and water stress in higher plants. Annual Review of Plant Physiolgy 35:299-319.

MUNNS, R. 1988. Why measure osmotic adjustment? Australian Journal of Plant Physiology 15:717-726.

PALTA, J.A., KOBATA, T., TURNER, N.C. \& FILLERY, I.R 1994. Remobilization of carbon and nitrogen in wheat as influenced by postanthesis water deficits. Crop Science $34: 118-124$
PAULA, F.M., FERREIRA, L.G.R. \& ROUALT, O.F.C. 1989 Alterações bioquímicas e fisiológicas em dois cultivares de algodão (Gossypium hirsutum L.) submetidos ao estresse hídrico. Revista Brasileira de Botânica 12:1-9.

RIAZI, A., MATSUDA, K. \& ARSLAN, A. 1985. Water-stress induced changes in concentrations of proline and other solutes in growing regions of young barley leaves. Journal of Experimental Botany 36:1716-1725.

RIZZINI, C.T. 1971. A flora do cerrado. In Simpósio sobre o cerrado. (M.G. Ferri, ed.). Edgard Blücher, São Paulo, p.75-96.

SILVA, S.P. 1996. Frutas do Brasil. Empresa de Artes, São Paulo.

SPIRO, R.G. 1966. Analysis of sugars found in glycoproteins. In Methods in enzymology: Complex carbohydrates (E.F. Neufeld, ed.). v. 8. Academic Press Inc., New York, p.3-26.

TURNER, N.C. 1986. Adaptation to water deficits: A changing perspective. Australian Journal of Plant Physiology 13:175-190.

TURNER, N.C. 1997. Further progress in crop water relations. In Advances in agronomy (D.L. Sparks, ed.). Academic Press, New York, p.293-337.

TURNER, N.C. \& JONES, M.M. 1980. Turgor maintenance by osmotic adjustment: A review and evaluation. In Adaptation on plants to water and high temperature stress (N.C. Turner \& J.P. Kramer, eds.). Wiley Interscience, New York, p. $87-103$

VIDAL, M.C., STACCIARINI-SERAPHIN, E. \& CÂMARA, H.H.L.L. 1999. Crescimento de plântulas de Solanum lycocarpum St. Hil. (Lobeira) em casa de vegetação. Acta Botanica Brasilica. 13:271-274. 